Revue

Revue de l'histoire des religions

de Ihistoire des religions

$3 \mid 2018$

Varia

VOLTAIRE, Euvres complètes, tome 65 C, Euvres de 1768, I, éd. David ADAMS, Alain SANDRIER et al.

Oxford, Voltaire Foundation, 2017

\title{
Riccardo Campi
}

\section{OpenEdition}

\section{Journals}

Édition électronique

URL : http://journals.openedition.org/rhr/9232

DOI : $10.4000 /$ rhr.9232

ISSN : 2105-2573

\section{Éditeur}

Armand Colin

\section{Édition imprimée}

Date de publication : 1 septembre 2018

Pagination : 580-583

ISBN : 978-2-200-93188-9

ISSN : 0035-1423

Référence électronique

Riccardo Campi, « Voltaire, EFuvres complètes, tome 65 C, EEuvres de 1768, I, éd. David Adams, Alain SANDrier et al. », Revue de l'histoire des religions [En ligne], 3 | 2018, mis en ligne le 01 septembre 2018, consulté le 13 janvier 2021. URL : http://journals.openedition.org/rhr/9232 ; DOI : https://doi.org/ $10.4000 /$ rhr.9232

Ce document a été généré automatiquement le 13 janvier 2021.

Tous droits réservés 


\title{
VOLTAIRE, Euvres complètes,
} tome 65 C, Euvres de 1768, I, éd. David ADAMS, Alain SANDRIER et al.

Oxford, Voltaire Foundation, 2017

\author{
Riccardo Campi
}

\section{RÉFÉRENCE}

VolTAIRE, CEuvres complètes, tome 65 C, Euvres de 1768, I, éd. David ADAMS, Alain SANDRIER et al., Oxford, Voltaire Foundation, 2017, xxx-340 p., $24 \mathrm{~cm}, 99$ £, ISBN

978-0-7294-1200-1.

1 Les textes dont se compose le tome $65 \mathrm{C}$ des Euvres complètes de Voltaire datent tous de l'année 1768, et la «Préface» (Marie-Hélène Cotoni, p.xVII-Xxx) rappelle opportunément au lecteur les événements majeurs de la vie de Voltaire qui la marquèrent. Dès la fin de février de cette année, la paisible existence au château de Ferney fut bouleversée par une de ces brouilles qui ont souvent troublé les relations entre le grand homme et sa nièce. Le motif de leur querelle était une affaire de manuscrits volés, copiés et divulgués à l'insu de Voltaire; la conséquence en fut que la nièce fut brusquement renvoyée pour avoir pris trop ouvertement la défense du coupable (en l'occurrence Jean-François de La Harpe) et Voltaire demeura seul à Ferney. La correspondance témoigne largement de ses cuisants regrets et de sa douleur pour la séparation: il nous reste une trentaine de lettres qu'il envoya à Mme Denis depuis le mois de mars jusqu'à la fin de l'année. Toutefois l'événement le plus éclatant ne regarde pas les ennuis domestiques et sentimentaux de Voltaire, qui en définitive ne concernent que sa vie privée; ce fut un geste qui fit parler toute l'Europe et scandalisa ou pour le moins étonna tout le monde, tant les nombreux ennemis de Voltaire (et en 
tout premier lieu l'évêque d'Annecy, Mgr Biord) que ses amis, "confrères" et admirateurs non moins nombreux : le jour de Pâques, Voltaire communia et de surcroît il osa prendre la parole pendant le service divin, pour inviter l'assistance à prier pour la santé de la reine, qui était très malade (il aura la hardiesse de répéter l'exploit l'année suivante, quoique "de manière plus contournée ", comme le précise Alain Sandrier, p. 113).

2 Ce geste retentissant et inouï se situe au moment où la campagne menée par Voltaire contre l'Infâme battait son plein, et par conséquent il sera légitime de le considérer comme une provocation ou un défi lancé aux hiérarchies de l'Église catholique au même titre que les innombrables brochures antichrétiennes, et autres "drogues" (c'est le mot de Voltaire, p. 45, n. 27), qui tout au long des années 1760 sortirent régulièrement de Ferney. En fait, le geste n'est pas étranger à la rédaction d'un texte polémique tel que la Profession de foi des théistes, qui commença à circuler vers le début de l'été 1768. Dans l'introduction au texte dont il a procuré l'édition critique, A. Sandrier remarque que la Profession, "d'une certaine façon, donne à lire ce que l'évêque Biord attend en vain au printemps 1768: si ce n'est une profession de foi "sincère" de Voltaire, à tout le moins une clarification de ses positions religieuses " (p.112). En effet, après le scandale de Pâques, la Profession peut être interprétée à bon escient comme une telle "clarification ", du plus célèbre et insoumis des diocésains de l'évêque Biord, même si elle n'était certainement pas faite pour combler les vœux du prélat. De ce petit texte de circonstance, écrit de toute évidence à la hâte et où foisonnent les autocitations et les passages recyclés d'autres ouvrages plus anciens comme le souligne l'éditeur (p. 121-123) -, Voltaire a composé « un condensé du Sermon des cinquante (pour la manière) et de Dieu et les hommes (pour la matière), deux œuvres qui l'encadrent chronologiquement»(p.123). Si cela contribue à en faire un texte moins original et en définitive mineur par rapport à d'autres pamphlets de Voltaire, on y trouvera pourtant l'essentiel de son déisme. De la condamnation des superstitions et du dogmatisme théologique à l'apologie de la tolérance qui serait la conséquence heureuse du déisme, toutes les scies de sa polémique antichrétienne y sont reprises, et rabâchées. Il serait inutile de les énumérer en détail : qu'il suffise de dire qu'aucune n'y manque.

3 Plus intéressant en revanche est de remarquer que la Profession, prétendument "traduite de l'allemand", s'adresse sans le nommer à un «prince» qui a «su porter sur le trône la philosophie et la tolérance ", en foulant « sous [ses] pieds les préjugés » (p. 133) : dès la parution du texte (mai-juin 1768), on appliqua immédiatement cette "dédicace » à Frédéric II. Et même si Voltaire ne l'autorisa jamais, il est toutefois tentant de reconnaître ce même " prince » dans celui dont parle le Fragment d'une lettre $d u$ Lord Bolingbroke, qu'on peut lire à la fin de ce même volume. Dans ce texte, aussi court qu'important, paru peu de mois après la Profession (octobre 1768), il est encore question d'un « très grand prince » qui « se ferait fort de gouverner très heureusement une nation considérable sans le secours de la superstition" (p.307) et cette fois l'identification du prince (que là encore Voltaire ne nomme pas) avec Frédéric II ne fait aucun doute. Quelle que soit la date effective du Fragment (Jean Dagen dénoue de manière très convaincante les difficultés pour l'établir, p.293-295), ce qui est remarquable c'est qu'en 1768 Voltaire fit imprimer coup sur coup ces deux petits textes où il prône une fois de plus son déisme, en se donnant pour caution dans les deux cas l'autorité et le prestige " philosophique » d'un despote éclairé tel que Frédéric II. Or, la 
«foi» déiste de celui-ci était plus que douteuse, son penchant pour l'athéisme, son cynisme en matière de politique religieuse et son mépris pour la foi et les croyances du peuple ignorant étant bien connus - et Voltaire devait les connaître mieux que tout autre dès les années de son séjour à la cour de Potsdam. Mais à une époque où commençaient à se déclarer parmi les "philosophes» de la nouvelle génération des tendances de plus en plus ouvertement athées, tout se passe comme si Voltaire voulait associer à tout prix son ancien protecteur à son programme déiste pour en imposer aux confrères plus jeunes. De manière plus ou moins explicite, la Profession et le Fragment témoignent d'un même souci de défendre le déisme contre le dogmatisme et le fanatisme des religions révélées (en premier lieu, bien entendu, le christianisme) mais aussi contre l'athéisme que prêchaient les philosophes les plus radicaux et cohérents, tels que les membres de la « coterie holbachique ». À la fin des années 1760, l'athéisme apparaissait aux yeux de Voltaire comme une menace aussi dangereuse pour le bon ordre de la société que celle que selon lui représentaient pour la "philosophie » les abus de la religion traditionnelle que son déisme était censé amender : car, d'après ses mots mêmes, "un très grand nombre de bons bourgeois, de prêtres, d'artisans même, ne croit pas plus aux superstitions que les confesseurs des princes, les ministres d'État et les médecins. Mais qu'arrive-t-il ? Ils ont assez de bon sens pour voir l'absurdité de nos dogmes; et ils ne sont ni assez instruits, ni assez sages pour pénétrer au-delà. Le Dieu qu'on nous annonce, disent-ils, est ridicule, donc il n'y a point de Dieu. Cette conclusion est aussi absurde que les dogmes qu'on leur prêche : et sur cette conclusion précipitée ils se jettent dans le crime, si un bon naturel ne les retient pas » (p. 308-309). Durant la décennie qui allait commencer, et qui sera la dernière de la vie de Voltaire, sa campagne contre l'Infâme se doublera ainsi d'une polémique tout aussi acharnée contre les tenants du matérialisme athée, en particulier contre le baron d'Holbach. Ce qui alimentera une « équivoque » dont Voltaire - comme le souligne J. Dagen (p. 301-302) « est menacé de ne pouvoir et de ne vouloir jamais se sauver » : malgré toute son ironie et la virulence de ses pamphlets antichrétiens, « en prêchant la loi morale et la clause du Dieu rémunérateur ", Voltaire aura toujours « l'air de ne pas rompre tout à fait avec une doctrine dont il conserve ce qu'on peut regarder comme l'essentiel : déisme ou théisme, le concept paraît assez jésuitique pour tolérer, voire préparer, les circonstances s'y prêtant, une renaissance chrétienne ».

4 Les autres textes recueillis dans ce tome des Cuvres complètes - Conseils raisonnables à Monsieur Bergier, pour la défense du christianisme; Remontrances des corps des pasteurs du Gévaudan, à Monsieur Rustan ; Traduction de l'Homélie du pasteur Bourn témoignent tous de cette équivoque, ou peut-être faudrait-il dire plutôt qu'ils révèlent tous l'obstination de Voltaire à mener son combat contre l'Infâme avec des armes dont le fil était désormais émoussé, l'idée d'une religion naturelle ayant perdu à la fin des années 1760 la vigueur polémique qu'elle avait lorsque Voltaire assena son premier coup de massue contre l'orthodoxie dans son Épître à Uranie, dont la rédaction remontait à une quarantaine d'années. Depuis lors le front de la lutte avait avancé, mais Voltaire ne paraît pas s'en apercevoir. D'où l'impression, comme le fait remarquer David Adams à propos des Conseils..., qu'il deal[s] with well-worn themes and ideas with which both the advocates and the opponents of toleration had long been familiar; critique qui vaut aussi pour les Remontrances... et la Traduction... Les notes des éditeurs (respectivement A. Sandrier, G. Gargett et M. Waddicor, D. Adams) permettent de repérer redites, autocitations et autres formes de recyclage. Reste que, malgré l'âge de l'auteur (qui avait soixante-quatorze ans à l'époque), ces textes de la vieillesse de 
Voltaire offrent chacun un exemple saisissant de son style polémique que personne ne put jamais imiter; c'est la variété des stratégies rhétoriques mises en œuvre par Voltaire qu'on pourra alors admirer une fois de plus dans ces pamphlets. On goûtera ainsi la manière toute théâtrale dont le vieil homme montre qu'il sait encore s'amuser et atteindre ses cibles, tout en amusant ses lecteurs - avec son goût pour la satire et la caricature grotesque des adversaires, les déguisements et les jeux de masques et de pseudonymies qui produisent toujours des effets ironiques d'une drôlerie qui, malgré la faiblesse des arguments, n'avait rien perdu en 1768 de la force et de l'efficacité dont avaient fait preuve ses écrits antichrétiens les plus hardis et les plus célèbres.

\section{AUTEURS}

RICCARDO CAMPI

Université de Bologne. 